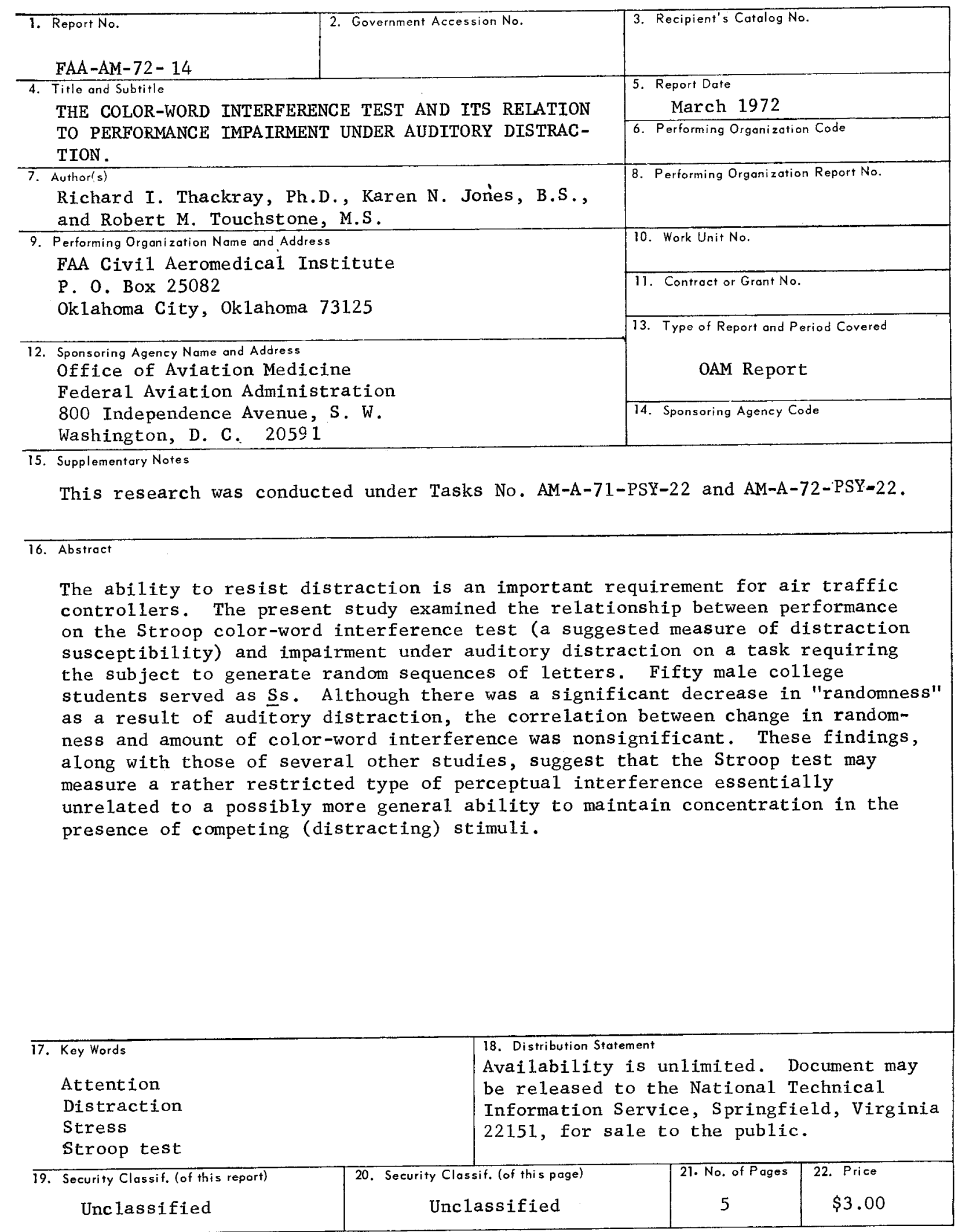

orm DOT F $1700.7(8.69)$ 



\section{THE COLOR-WORD INTERFERENCE TEST AND ITS RELATION TO PERFORMANCE IMPAJRMENT UNDER AUDITORY DISTRACTION}

\section{Introduction.}

The Stroop color-word interference test ${ }^{11}$ has been suggested as a possible measure of the ability to attend selectively to certain stimuli in the presence of irrelevant and competing stimuli. ${ }^{58}$ This ability is of obvious importance in certain ariation occupations (e.g., air traffic control) where sustained attention in the presence of anditory or visual distraction is often required. In view of the relative lack of tests to measure "distractibility," 8 research to evaluate the usefulness of this particular test as a possible predictor of performance impairment under distraction would seem indicated.

A previous study by Thackray and Jones ${ }^{12}$ described the development of a laboratory version of the Stroop test for use in distraction research and examined the influence of simultaneously presented relevant (conflicting color names) and irrelevant (random numbers) auditory distraction on the color-word interference effect. Although several other studies had employed conflicting auditory stimuli in conjunction with the visually-presented color-word stimuli, ${ }^{3}$ these studies were primarily concerned with the use of the Stroop test as a stressor and neither actually examined the extent of additional interference which they assumed would result from the anditory stimuli. Consequently, it seemed desirable, for purposes of test development, to determine the magnitude of the increase in interference which might result from the addition of conflicting auditory stimuli.

The method developed by Thackray and Jones ${ }^{12}$ for presenting the visual color-word stimuli was successful in eliciting the characterisic Stroop effect.* However, there were no

\footnotetext{
*Increase in reaction time from Part II (naming colors of colored rectangles) to Part III (naming colors of ink $\mathrm{n}$ which incongruent color-names are printed).
}

significant performance or physiological differences between the group which received the standard Stroop conditions and the groups which received the standard Stroop conditions plus relevant or irrelevant auditory distraction. This indicated that the addition of auditory "distraction" did not augment or modify the basic effect in any way.

If the color-word interference test measures a form of general ability to sustain attention in the presence of interfering stimuli, one might have expected the addition of the competing auditory stimuli to have resulted in at least some increase in response times to the visual stimuli. The lack of effect of the auditory stimuli suggests that the Stroop test may reflect susceptibility to a rather specific kind of perceptual interference. If this is the case, the test may possibly have limited usefulness as a measure of general distractibility.

The present study was conducted to evaluate this possibility. Susceptibility to interference, as measured by the Stroop test, was compared with extent of performance impairment on a task known to be adversely affected by distraction. The task chosen was random generation of letters of the alphabet. This task has been used in several recent studies concerned with deployment of attention and has been shown to be quite sensitive to the effects of distracting auditory stimuli. ${ }^{10}{ }^{14}$ The usual procedure consists of instructing subjects $\left(S_{\mathrm{s}}\right)$ to try to generate letters of the alphabet (or numbers) in "random" order at some experimenter-determined rate. Amount of change in randomness under auditory distraction reflects the degree of success with which $S \mathrm{~s}$ are able to sustain attention to the primary task and exclude or ignore the irrelevant auditory stimuli.

\section{Method.}

A. Subjects. Fifty paid male university students between the ages of 18 and 25 were 
employed as $S$ s. All were right-handed and had no reported color-rision or hearing deficiencies.

B. Apparatus. The $S$ 's console containing all of the equipment necessary for him to perform the task was located in one room with the programming and recording equipment located in an adjoining room.

The basic apparatus for the Random Generation (RG) task consisted of a pair of Koss Pro/4AA headphones for presenting the task instructions and the distraction stimuli, a Sony F-25 microphone, and a pair of small "stimulus" lights for pacing the $S$ 's responses. The lights were located directly in front of the $S$ and flashed momentarily every two seconds. They were actuated automatically by a set of Hunter timers. Leads from the microphone were connected to an amplifier and a second set of headphones to enable monitoring and recording of the $S$ 's verbal responses.

For the Stroop test, slides were projected onto a rear projection screen by means of a Lafayette Model KT-800 Automatic Projection Tachistoscope. The stimuli were $35 \mathrm{~mm}$ slides of words or colored rectangles and were $27 \mathrm{~mm}$ high and $68 \mathrm{~mm}$ wide when projected on the screen. A small white cross in the middle of the screen served as a fixation point. Response buttons with the stimulus words printed above them were"located to the $S$ 's right approximately three inches abore the shelf on which the $S$ rested his hand between responses. A series of Davis Scientific Instrument timers was used to advance the slides and actuate the shutter. Inter-stimulus intervals were three seconds with exposure durations of 0.5 seconds. The $S$ 's response and reaction time (in msec.) to each slide was recorded on paper tape by means of a Welford Mark V SETAR (Welford Bioelectronics Enterprises).

C. Procedure. Ipon arrival, the $S$ was taken to the experimental room and the experimenter $(E)$ played a tape recording of the initial orientation instructions and the instructions for the first task (RG task).* In the instructions for the RG task the $S$ was told that his task would be to generate a series of random letters

* All $S \mathrm{~S}$ received the $\mathrm{RG}$ task prior to being administered the Stroop test. This was felt desirable in order to eliminate the possible influence of the particular quasi-random order employed with the Stroop stimuli on the S's conception of randomness. using all 26 letters of the alphabet. The $S$ was given Baddeley's standard instructions ${ }^{2}$ in which he was asked to imagine that on each trial he was drawing a letter from a hat, saying the letter out loud, and returning the letter to the hat so that on each trial every letter would be present and have an equal chance of being chosen. He was also asked to keep in mind that such a series of letters would be completely random and would not be likely to consist of words, alphabetic sequences, etc.

The $S$ was told that each flashing of the lights was designated as a trial and was given a practice series of 20 trials. He was informed that the whole task would take about 25 minutes and would be divided into three parts with a short rest period between parts. (Each part contained 150 trials and lasted approximately five minutes with 2-min. rest periods between parts.) During the first part, the $S$ worked in silence. At the beginning of the second part, he was informed that he would hear random letters through his headphones, but that he was to try to ignore them. A continuous 5-min. tape recording consisting of the letters $\mathrm{B}, \mathrm{D}, \mathrm{F}, \mathrm{G}, \mathrm{I}, \mathrm{K}, \mathrm{M}, \mathrm{N}, \mathrm{Q}$, $\mathrm{R}, \mathrm{T}, \mathrm{V}$, and $\mathrm{Y}$ arranged in a random order was presented to the $S$ during this part. Intervals between letters raried randomly from approximately 0.5 sec. to 1.0 sec. The third part was identical to the first. At the end of the RG task: the $E$ went into the $S$ 's room, removed the head. phones, microphone, and stimulus lights and set up the equipment for the Stroop test.

The $S$ was told that this next task would have three parts, each of which would be explainec separately, and that there would be brief res periods between parts. The $S$ was instructed tc press the response button corresponding to thi stimulus presented on the screen. He was asker to press the buttons as rapidly as possible anc then look back at the fixation spot. For eac] part, there were 4 practice- and 72 test-stimulu slides. There were 2 -min. rest periods betwee] parts which allowed time for the $E$ to change th slides. Stimuli in each part were arranged in quasi-random order, with the restrictions tha each stimulus appear an equal number of time and that no two adjacent stimuli be the same.

The stimuli for Part I were the word BROWN, GREEN, ORANGE, and PURPL] printed in black. 
The stimuli for Part II were colored rectangles rresponding to the words presented in Part I. The stimuli for Part III consisted of the conintional Stroop color-word stimuli, i.e., color mes used in Part I printed in incongruent lored ink. The $S$ was instructed to ignore the ord itself and respond only to the color of the $k$.

Duration of the Stroop test was approximately minutes.

D. Measurement and Scoring of Data. For e Stroop test, response times to the 72 stimuli each part were obtained for each $S$ and zans were computed. Randomness over the 0 trials in each of the three parts of the I task was measured by the entropy formula $=\log _{2} \mathrm{~N}-(1 / \mathrm{N}) \Sigma n_{i} \log _{2} n_{i}$ where $\mathrm{N}$ is the num$\therefore$ of trials and $n_{i}$ is the frequency of usage of sh letter of the alphabet. The higher the value $H$, the more random the series. ${ }^{1}$

\section{[. Results.}

Mean $H$-ralues for the three parts of the $R G$ $\mathrm{k}$ are shown in Table 1. As expected the effect the auditory distraction was to reduce randomis.

3L.E 1. Mean $H$-values for the pre-distraction, distraction, and post-distraction parts.

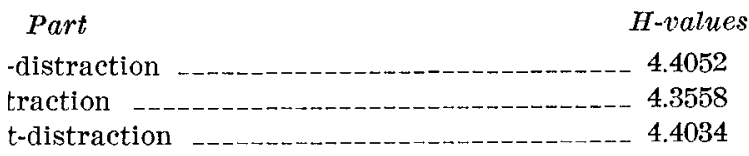

1 repeated measures analysis of rariance reled this reduction to be significant $(\mathrm{F}=5.12$; $=2,98 ; p<.01)$. Although the magnitude of effect appears small, the $H$-values obtained the nondistraction and distraction parts are tually identical to those obtained by Schimek I Wachtel ${ }^{10}$ under comparable conditions.

$\mathrm{n}$ order to obtain a baseline measure of domness, $H$-ralues for the pre- and postraction parts were first tested for statistical ivalence using Tukey's HSD test. ${ }^{7}$ The test anled that the difference between these two ts was nonsignificant $(p>.05)$. Consequently, $H$-values for these two parts were combined

change in randomness was determined by tracting each $S^{\prime} s H$-value for the second part $\mathrm{n}$ his mean value for the pre- and postraction parts.

'or the color-word interference test, mean sonse times were 851 and 1015 msecs. for Parts
II and III respectively. These values closely approximate those obtained for the comparable stimulus conditions in the previous study by Thackray and Jones. ${ }^{12}$

Although a variety of scores have been suggested as measures of the color-word interference effect, a factor analysis of these measures by .Jensen ${ }^{4}$ has demonstrated a simple difference score between the color-word part (Part III) and the color part (Part II) to be the most effective measure of the interference effect. Consequently, the product-moment correlation between this measure of color-word interference and the difference scores on the RG task was computed. Although the correlation was positive, it was quite low and nonsignificant $(r=.12$; $\mathrm{p}>.05)$. No improvement was obtained when the same scores for both tests were expressed in terms of percent change.

\section{Discussion.}

The results of the present study confirm earlier findings ${ }^{10} 14$ that the ability to generate random letters or digits is significantly impaired when $S$ s are required to perform this task in the presence of auditory distraction. Indiridual differences in the extent of this impairment, however, were found to be completely unrelated to differences in the magnitude of color-word interference on the Stroop test. This lack of relationship supports the implications of the results obtained in the previous study by Thackray and Jones ${ }^{12}$ that the Stroop test reflects susceptibility to a limited kind of perceptual interference which may be essentially unrelated to what is commonly thought of as distractibility.

In a factor analytic study designed to investigate possible correlates of field dependenceindependence, Karp ${ }^{6}$ identified two clusters of factors which were associated with two rather different types of visual distraction situations. One cluster of factors was represented in general by tests in which the critical stimulus is presented in the presence of irrelerant stimuli which compete with, but do not distort or modify, the basic properties of the central stimulus. An example of such tests would be the digit symbol subtest of the Wechsler Adult Intelligence Scale. Presumably tests loading on this cluster reflect an ability typically implied by the common conception of concentration, i.e., the ability to sustain attention in the presence of potentially interfering ("distracting") stimuli. 
The second cluster of factors was represented by tests in which the figural properties of the central stimulus are actually changed by the irrelevant stimuli and new, competing gestalts are formed. An example would be the embeddedfigure test. Although some degree of correlation exists between these two clusters of factors, Karp apparently feels that the ability to overcome the effects of embedding contexts represents a factorily different ability than the ability to sustain concentration in the presence of "distracting" stimuli.

While Karp did not employ the Stroop test in his factor analysis, other investigators have examined the relationship between this test and the embedded figures test.5 Moderate correlations ranging from 0.36 to 0.54 have generally been reported. This would suggest that the Stroop test might well have loaded on the same factors as the embedded figures test had it been included in Karp's study. It might also suggest that had the embedded figures test been employed in the present study it would hare been unrelated to performance change on the random generation task under auditory distraction. This in fact was one of the findings of the Schimek and Wachtel ${ }^{10}$ study. Their results failed to support the hypothesis that field dependent $S$ s (as determined by scores on the embedded figures test) would show greater impairment on the random generation task than field independent $S_{\mathrm{s}}$. No relationship whatsoever was found between any of the measures of field dependence and either baseline levels or change in randomness und distraction.

Wachtel ${ }^{13}$ has noted that a controversy exi: as to whether such tests as the Stroop test a: the embedded figures test primarily reflect $t$ ability to extract items from embedding conte: or whether they represent a more general capac: to selectively direct attention to relevant ratl than competing irrelerant stimuli. The findir of the studies reviewed here taken together w: those of the present investigation strongly si gest that "distractibility" as measured by 1 color-word interference test may be more clos related to the rather restricted ability to ov come the effects of embedding contexts than the more general capacity to attend to a task the presence of competing irrelevant stim. Additional support for this is provided Mandell ${ }^{8}$ who found that performance of c] dren on the Stroop test was unrelated to teac. ratings of distractibility.

More promising, perhaps, as a measure of c tractibility is the task used in the present stı as the "criterion" measure. The ability to $g$ erate random letters or digits has been clea shown to be impaired in the presence of audit distraction. As Schimek and Wachtel ${ }^{10}$ sugg the measure of randomness appears to br promising one for the study of individual dif ences in attention deployment. Further resea using change in randomness under distractior a predictor variable would seem indicated. 


\section{REFERENCES}

- Attneave, F.: Application of Information Theory to Psychology, New York: Holt, Rinehart and Winston, $1959,120 \mathrm{p}$.

- Baddeley, A. D.: The Capacity for Generating Information by Randomization, QUARTERLY JOURNAL OF EXPERIMENTAL PSYCHOLOGY, 18:119-129, 1966.

Frankenhaeuser, M., J. Froberg, R. Hagdahl, A. Rissler, C. Bjorkvall, and B. Wolff: Physiological, Behavioral, and Subjective Indices of Habituation to Psychological Stress, PHYSIOLOGY AND BEHAVIOR, $2: 229-237,1967$.

Jensen, A. R.: Scoring the Stroop Test, ACTA PSYCHOLOGICA, 24 :398-408, 1965.

Jensen, A. R., and W. D. Rohwer: The Stroop ColorWord Test: A Review, ACTA PSYCHOLOGICA, $25: 36-93,1966$.

Karp, S. A.: Field Dependence and Overcoming Embeddedness, JOURNAL OF CONSULTING PSYCHOLOGY, 27 :294-302, 1963.

Kirk, R. E.: Experimental Design: Procedures for the Behavioral Sciences, Belmont, California: Brooks/Cole, 1968, 577 p.

Mandell, S. J.: Children's Resistance to Competing and Distracting Stimuli in the Classroom, Doctoral dissertation, University of Southern California, Los Angeles, (University Microfilms, Ann Arbor, Michigan, No. 66-11, 578), 1966.

9. Rissler, A.: Performance in a Task Involving Perceptual Conflict. In Levi, L. (Ed.), Emotional Stress, New York: American Elsevier Publishing Co., Inc., 1965, $280 \mathrm{p}$.

10. Schimek, J. G., and P. L. Wachtel: Exploration of Effects of Distraction, Competing Tasks and Cognitive Style on Attention Deployment, PERCEPTUAL AND MOTOR SKILLS, $28: 567-574,1969$.

11. Stroop, J. R.: Studies of Interference in Serial Verbal Reactions, JOURNAL OF EXPERIMENTAL PSYCHOLOGY, 18:643-662, 1935.

12. Thackray, R. I., and K. N. Jones: Level of Arousal During Stroop Performance: Effects of Speed Stress and "Distraction", PSYCHONOMIC SCIENCE, $23: 133-135,1971$.

13. Wachtel, P. L.: Conceptions of Broad and Narrow Attention, PSYCHOLOGICAL BULLETIN, 68:417429, 1967.

14. Wolitzky, D. I., and D. P. Spence: Individual Consistencies in the Random Generation of Choices, PERCEPTUAL AND MOTOR SKILIS, 26:12111214, 1968. 
